\title{
A avaliação em geometria espacial feita pelo Simave
}

ODALÉA APARECIDA VIANA*

\section{RESUMO}

Com base em pressupostos teóricos da Psicologia da Educação Matemática, este trabalho tem como objetivos: (a) analisar as questóes de matemática relativas à geometria espacial, do $9^{\circ}$ ano do ensino fundamental e do $3^{\circ}$ ano do ensino médio, das provas Proeb/Simave realizadas em 2006, 2007 e 2008, quanto à forma de apresentaçáo das informaçóes, à estrutura conceitual requerida, ao nível de formação conceitual em geometria e às habilidades espaciais necessárias; e (b) analisar o desempenho dos alunos nessas questóes. Verificou-se que a maioria delas exigia nível elementar de formação conceitual, a habilidade requerida (planificação) era de pouca complexidade, e os problemas exigiam poucas relaçōes. A porcentagem de acertos em geometria espacial ficou em torno de $41 \%$, desempenho considerado pouco satisfatório. Espera-se que sejam desencadeadas açóes que possam melhorar o rendimento em geometria espacial e revistos alguns descritores das Matrizes de Referência relativos a Espaço e Forma e Grandezas e Medidas.

Palavras-chave: Avaliação da aprendizagem, Educação básica, Conceito matemático, Ensino de geometria.

\section{RESUMEN}

En base a supuestos teóricos de la psicología de la educación matemática, este trabajo tiene como objetivos: (a) analizar las cuestiones de matemática relativas a geometría espacial de las pruebas Proeb/Simave realizadas en 2006, 2007 y 2008, aplicadas en el $9^{\circ}$ año de la enseñanza

\footnotetext{
* Professora Adjunto II da Faculdade de Ciências Integradas do Pontal - Universidade Federal de Uberlândia (UFU) (odalea@pontal.ufu.br).
} 
fundamental y en el $3^{\circ}$ ańo de la enseñanza media. Se analiza la forma de presentación de la información, la estructura conceptual requerida, el nivel de formación conceptual en geometría y las habilidades espaciales necesarias; y (b) analizar el desempeño de los alumnos en estas cuestiones. Se verificó que la mayoría de los temas exigía un nivel elemental de formación conceptual; la habilidad requerida (planificación) era de poca complejidad y los problemas exigían pocas relaciones. El porcentaje de acierto en las cuestiones de geometría espacial fue de alrededor del $41 \%$, un desempeño considerado poco satisfactorio. Se espera que se desencadenen acciones que puedan mejorar el rendimiento en geometría espacial, y que se revean algunos descriptores de las Matrices de Referencia relativos a Espacio y Forma y a Medidas.

Palabras clave: Evaluación del aprendizaje, Enseñanza básica, Formación del concepto matemático, Enseñanza de geometría.

\section{ABSTRACT}

This paper is based on theoretical assumptions of the psychology of mathematics teaching, and it has the following objectives: (a) to analyze mathematical questions related to spatial geometry, from the $9^{\text {th }}$ grade of elementary school and $3^{\text {rd }}$ grade of middle school, of the Proeb/Simave tests given in 2006, 2007 and 2008, concerning the way information is presented, the required conceptual structure, the level of conceptual formation in geometry, and the spatial abilities needed; and (b) to analyze the students' performance in these questions. It was observed that most questions required an elementary level of conceptual formation; the required ability (turning into a plane) was of low complexity and the problems demanded few relations. The percentage of correct answers in spatial geometry was around $41 \%$, a performance that is not considered very satisfactory. It is hoped that steps will be taken to improve the results in spatial geometry, and that some descriptors of Reference Matrixes related to Space and Form and Magnitudes and Measures will be revised.

Keywords: Learning assessment, Basic education, Mathematical concept, Geometry teaching. 


\section{INTRODUÇÃO}

Entre as ações do Sistema Mineiro de Avaliação da Educação Pública (Simave), destaca-se o Programa de Avaliação da Rede Pública (Proeb), que avalia o rendimento de todos os alunos que estejam cursando o $5^{\circ}$ e $9^{\circ}$ anos do ensino fundamental ( $4^{\mathrm{a}}$ e $8^{\mathrm{a}}$ séries/ciclo correspondente) e o $3^{\circ}$ ano do ensino médio. De acordo com a apresentação do programa, os testes têm por objetivo mensurar as habilidades desenvolvidas pelos estudantes, sendo estas consideradas características de competências cognitivas.

O presente trabalho buscou destacar a matemática, no item espaço e forma, sendo que este bloco corresponde aos conteúdos de geometria. Pesquisas têm mostrado o grau de dificuldade que alunos do ensino básico e superior enfrentam, quando respondem questôes com tais conteúdos. Alguns trabalhos enfatizam as questóes referentes à formaçáo de conceitos (Pirola; Brito, 2001; Rezi, 2001; Viana, 2000), à solução de problemas (Pirola, 2000) e às habilidades (Viana, 2005).

Os avanços da psicologia cognitiva têm fornecido teorias que ajudam a compreender como as pessoas pensam, representam o conhecimento, formam imagens, raciocinam espacialmente e solucionam problemas (Kosslyn, 1995; Sternberg, 2000). Na mesma linha, tem sido estudada a construçáo do conhecimento em geometria, baseada em níveis de formaçáo conceitual de Van Hiele (1986), teoria também utilizada neste trabalho.

O estudo de Viana (2005) isolou alguns subcomponentes (decomposiçâo, formaçáo e identificação de polígonos no espaço, secção, planificaçáo, projeção e revolução) da habilidade matemática, conforme definida por Krutetsky (1976), que foram evidenciados na solução de tarefas, tendo encontrado correlação entre três variáveis: esse componente espacial, o raciocínio espacial e o desempenho escolar em geometria. A pesquisa ainda analisou problemas de geometria espacial comuns no ensino médio quanto ao tipo de estrutura conceitual (aritmética, algébrica, geométrica, espacial) requerida para resolvê-los. Estas estruturas e os subcomponentes da habilidade matemática foram utilizados neste artigo.

A Matriz de Referência de Matemática do Proeb focaliza, no tema Espaço e Forma, alguns descritores relativos à geometria plana e espacial. Dentre esses, chama a atenção o descritor D2 da oitava série, definido como a habilidade para identificar propriedades de figuras tridimensionais, relacionando-as com suas planificaçóes. Já no ensino médio, D1 é identificado como a habilidade de reconhecer a planificação de figuras tridimensionais mais usuais (prismas, pirâmides, 
paralelepípedo, cubo, cilindro e cone). No tema Grandezas e Medidas há a descrição de D13 (utilizar as noçôes de volume) e de D9 (resolver situaçóes-problema envolvendo o volume de um sólido: prisma, pirâmide, cilindro, cone, esfera, paralelepípedo).

Considerou-se que nâo havia clareza quanto à especificidade, ao grau de complexidade da habilidade e ao nível de formação conceitual requeridos pelas questóes da prova. Observou-se também que faltava elencar outras habilidades relativas à geometria espacial, conforme apontam os Parâmetros Curriculares Nacionais e os estudos já citados.

Diante do exposto, o trabalho ${ }^{1}$ apresentado é composto por duas questóes, sendo que a primeira delas se refere à análise teórica do tipo de estrutura conceitual (aritmética, geométrica, espacial, mista) requerida pelas questôes das provas Proeb de matemática para o ensino fundamental e o ensino médio, relativas ao conteúdo de geometria espacial de 2006, 2007 e 2008. Serão analisados também o nível de formaçâo conceitual e a habilidade requerida pelos problemas.

A outra questáo se refere à avaliaçâo do desempenho dos alunos nessas questóes de geometria espacial das provas Proeb, com base nos dados fornecidos pelo Simave, em que se pode verificar, quantitativamente e qualitativamente, qual o nível de desenvolvimento que alunos do ensino fundamental e médio possuem acerca da formação conceitual e das habilidades citadas.

Considera-se que as análises feitas poderão constituir-se num referencial a ser usado pela Secretaria da Educação, no que diz respeito às açóes que levem à melhoria da qualidade de ensino em matemática, uma vez que permitirão o aprofundamento das questôes relativas ao processo de ensino-aprendizagem, ao desenvolvimento de habilidades e aos instrumentos de avaliação, e também uma melhor definição das matrizes de referência para os testes cognitivos.

\section{FUNDAMENTAÇÃO TEÓRICA}

Este trabalho baseia-se nos fundamentos teóricos da psicologia cognitiva, em especial da linha do processamento da informaçáo, que tentam explicar os processos que subjazem ao pensamento inteligente, como aqueles relativos à percepçáo, à representação, à aprendizagem, à memória, à atenção, ao raciocínio, à formação conceitual e à habilidade na solução de problemas.

${ }^{1}$ Este trabalho é parte de uma pesquisa financiada pela Fundaçáo de Amparo à Pesquisa do Estado de Minas Gerais (Fapemig). 


\subsection{A habilidade matemática e o componente espacial}

No ambiente escolar, embora existam muitos fatores que determinam as diferenças de rendimento em matemática, podem ser destacadas certas características individuais que foram estudadas pelo psicólogo russo Vadim Andreevich Krutetsky (1976) em um amplo programa de pesquisa realizado de 1955 a 1966, tendo como sujeitos crianças escolarizadas. A chamada prontidão para uma atividade foi descrita pelo autor como uma estrutura que envolve as habilidades do sujeito e um conjunto de condiçóes psicológicas que permitem a ele ter sucesso na execução de uma atividade ou tarefa - uma atitude positiva com relação à atividade (interesses, afetos, etc.), traços de personalidade, estado mental, conhecimentos, destrezas e hábitos.

No caso específico da matemática escolar, a habilidade matemática-caracterizada pela rapidez, facilidade e meticulosidade no domínio dos conhecimentos, destrezas e hábitos - influenciaria o sucesso do indivíduo nessa disciplina.

Utilizando problemas aritméticos, algébricos e geométricos, o autor diferenciou os processos cognitivos que os sujeitos utilizavam para resolvê-los e classificou-os em viso-pictóricos e analíticos. Os alunos classificados no tipo pictórico ou geométrico têm um pensamento caracterizado por um componente viso-pictórico muito bem desenvolvido, solucionando rapidamente as questões que necessitam da habilidade visual.

Com base nos problemas propostos por Krutetsky (1976), Viana (2005) procurou entender melhor o componente espacial da habilidade matemática, estudando alguns fatores que explicariam a habilidade de alunos do ensino médio ao lidar com tarefas relativas à geometria espacial. A análise quantitativa do componente espacial da habilidade matemática e a análise qualitativa das operaçóes com imagens mentais ${ }^{2}$, realizadas pelos sujeitos com melhor e pior desempenho, permitiram identificar alguns subcomponentes dessa habilidade, tais como:

a) habilidade para sistematizar a contagem de cubos em um arranjo;

b) habilidade para identificar polígonos resultantes da união de pontos no espaço;

c) habilidade para seccionar os sólidos por meio de planos imaginários;

${ }^{2}$ A teoria de Kosslyn (1995) defende a hipótese de que a imagem mental visual e a percepçáo compartilham mecanismos comuns. Seu modelo computacional explica, com base em aspectos neurológicos, como o organismo processa as informaçóes visuais por meio de certas áreas do cérebro e de suas conexôes. Uma imagem mental visual é um tipo de ativação do campo visual que náo é causada por estímulo sensorial imediato. Uma tarefa de imaginação envolve quatro classes de habilidades: geração ou formação de imagens; inspeção de imagem; manutenção da imagem e a transformação de imagens. 
d) habilidade para planificar figuras tridimensionais, seja rebatendo os planos das faces de poliedros, seja desenvolvendo as superfícies laterais de corpos redondos, sendo que os desenhos apresentam simetria ou indicam desdobramentos em continuidade;

e) habilidade para projetar ortogonalmente sólidos formados por cubinhos;

f) habilidade para identificar figuras planas geradoras de sólidos de revoluçáo.

Esses subcomponentes foram utilizados para analisar as questōes relativas a este trabalho.

\subsection{Os níveis de formação conceitual em geometria espacial}

As questóes que requerem estrutura geométrica podem ser analisadas pelo nível de formação conceitual, de acordo com o modelo de Van Hiele (1986). Segundo o modelo, existem cinco níveis de compreensão, e os alunos progridem nesta sequência hierárquica, enquanto aprendem geometria.

O Nivel 1 é o de reconhecimento e nesse estágio inicial o aluno percebe os conceitos geométricos como entidades totais, não vê componentes ou atributos.

No Nível 2, ou análise, o estudante reconhece as partes de uma figura, começa a analisar as suas propriedades e utiliza algumas delas para resolver certos problemas.

No Nível 3 o aprendiz é capaz de explicar relaçóes entre propriedades, tanto das figuras quanto entre elas, e de formar classes de figuras. Consegue entender a importância de definiçōes acuradas, acompanha e formula argumentos informais, mas não compreende o significado da deduçáo como um todo ou o papel dos axiomas.

O Nível 4, de dedução, é marcado pela compreensão do significado desta como maneira de estabelecer a teoria geométrica no contexto de um sistema axiomático. Um aluno nesse nível compreende as condições necessárias e suficientes para uma afirmação e é capaz de construir demonstraçóes, utilizando a linguagem formal.

Finalmente, no Nível 5 o estudante é capaz de trabalhar em vários sistemas axiomáticos, pode estudar geometrias não-euclidianas e comparar diferentes sistemas.

A teoria de Van Hiele tem sido amplamente utilizada em pesquisas direcionadas ao uso de novas metodologias no ensino, na avaliaçáo de níveis de desenvolvimento do pensamento geométrico de alunos e também na análise de questóes de provas oficiais, como pode ser visto em Resende e Viana (2008). 


\subsection{Os problemas de geometria espacial}

$\mathrm{Na}$ análise dos problemas que constam de livros, exames vestibulares, concursos e outras provas, e que se referem à geometria espacial, podem ser verificadas três características importantes.

Uma delas refere-se ao seu enunciado, ou seja, ao modo como é feita a apresentação das informaçóes iniciais e daquelas que indicam as operaçóes necessárias para o processo de solução. Muitos problemas apresentam as informaçóes na forma predominantemente pictórica: o próprio desenho, em geral mostrando um ponto de vista em perspectiva, já traz quase todos os dados necessários para a obtençáo da informação geométrica e também para o seu processamento. Em outros casos, a informaçáo é predominantemente verbal, ou seja, os dados do problema aparecem descritos na forma de palavras. Há também os enunciados mistos, quando uma parte dos dados é apresentada na forma pictórica e outra na forma verbal.

Para solucionar questóes de geometria é necessário que o aluno tenha formado uma estrutura conceitual. Mas, em muitos casos, a experiência mostra que os estudantes sabem os conceitos e os princípios geométricos relativos ao problema, mas erram a resposta porque não dominam cálculo aritmético ou algébrico. Assim, vários são os problemas que exigem uma estrutura conceitual complexa e predominantemente aritmética ou algébrica, porém os conceitos geométricos envolvidos são relativamente simples. São exemplos desse tipo aqueles cuja solução requer aplicação de fórmulas e cálculo aritmético e/ou algébrico. Em outros casos, a estrutura é predominantemente geométrica, ou seja, a soluçáo exige que o aluno saiba conceitos e princípios geométricos, que, na maioria das vezes, não aparecem explícitos no enunciado. Outros têm estrutura predominantemente espacial, pois a sua solução requer raciocínio espacial $e$, às vezes, não necessita de cálculos ou conceitos geométricos mais complexos. Há, ainda, os problemas com estrutura mista: requerem conceitos geométricos, aritméticos e algébricos e também exigem raciocínio espacial.

No entanto, os problemas também podem ser classificados de acordo com as competências mais exigidas para sua solução. Utilizando-se as operaçóes relativas ao componente espacial da habilidade matemática, os problemas podem propor: contagem de cubos, formação de polígonos, secçáo, planificaçáa, revolução e projeção.

Essa classificação tem facilitado a análise de questōes de provas oficiais relativas à geometria espacial, conforme pode ser visto em Viana (2009a; 2009b). 


\subsection{O Simave/Proeb e as matrizes de referência}

O Sistema Mineiro de Avaliação da Educaçáo Pública (Simave) foi criado pela Secretaria de Estado de Educação de Minas Gerais, em 2000. As avaliaçôes em larga escala, de acordo com o Boletim Pedagógico (BP) emitido pela secretaria, sáo feitas para conhecer o funcionamento do sistema público de educação tendo em vista a ocorrência de equilíbrio entre o desempenho e o fluxo escolar (Minas Gerais, 2008).

O objetivo do sistema é desenvolver programas de avaliaçáo integrados, cujos resultados apresentem informaçóes importantes para o planejamento de açóes em todos os níveis do sistema de ensino. De acordo com o documento, o Simave apontaria as prioridades educacionais tanto para professores, especialistas e diretores quanto para os gestores do sistema, o que é fundamental na definição de açóes para uma educaçáo eficaz. O Simave é constituído por três diferentes programas de avaliaçâo: o Proalfa, o Proeb e o Paae.

O Programa de Avaliaçáo da Rede Pública de Educação Básica (Proeb) tem por objetivo avaliar as escolas da rede pública, no que concerne a habilidades e competências desenvolvidas em Língua Portuguesa e Matemática. Desde 2001, o programa avalia alunos que se encontram no $5^{\circ}$ e $9^{\circ}$ anos do ensino fundamental e no $3^{\circ}$ ano do ensino médio da rede municipal e estadual, conforme tabela 1 .

Tabela 1 - Avaliações feitas pelo Proeb

\begin{tabular}{llcccc}
\hline \multirow{2}{*}{ Ano } & Avaliação & \multicolumn{2}{c}{ No de escolas $^{2}$} & \multicolumn{2}{c}{$\mathbf{N}^{\circ}$ de alunos } \\
\cline { 3 - 6 } & & $\begin{array}{c}\text { Rede } \\
\text { estadual }\end{array}$ & $\begin{array}{c}\text { Rede } \\
\text { municipal }\end{array}$ & $\begin{array}{c}\text { Rede } \\
\text { estadual }\end{array}$ & $\begin{array}{c}\text { Rede } \\
\text { municipal }\end{array}$ \\
\hline \multirow{2}{*}{2000} & L. Portuguesa & 3.378 & 69 & 486.552 & 4.737 \\
& Matemática & 3.378 & 69 & 484.996 & 4.680 \\
2001 & C. Humanase C. da Natureza & 3.588 & 1015 & 453.739 & 28.613 \\
2002 & L. Portuguesa & 3.594 & 1.463 & 467.272 & 77.290 \\
2003 & Matemática & 3.661 & 1.116 & 459.253 & 60.088 \\
2006 & L. Portuguesa & 3.401 & 2.736 & 455.964 & 182.813 \\
& Matemática & 3.401 & 2.736 & 441.590 & 179.839 \\
2007 & L. Portuguesa & 3.658 & 6.383 & 447.683 & 224.298 \\
& Matemática & 3.319 & 5.667 & 436.842 & 224.661 \\
2008 & L. Portuguesa & 3.682 & 6528 & 444.532 & 217.534 \\
& Matemática & 3.677 & 6521 & 431.547 & 215.766 \\
\hline
\end{tabular}

As matrizes do Simave (Minas Gerais, 2009) foram organizadas com base nos pressupostos teóricos sobre as habilidades básicas a serem avaliadas em cada período de escolarização, tendo como referência os Parâmetros Curriculares Nacionais, as Diretrizes Curriculares Nacionais da Educaçáo e o Conteúdo Básico Comum do Estado de Minas Gerais (CBC). 
De acordo com o documento,

Uma Matriz de Referência é composta por um conjunto de descritores, os quais explicitam dois pontos básicos do que se pretende avaliar: o conteúdo programático a ser avaliado em cada período de escolarização e o nivel de operação mental necessário para a realização de determinadas tarefas. Tais descritores são selecionados para compor a matriz, considerando-se aquilo que pode ser avaliado por meio de um teste de múltipla escolha, cujos itens implicam a seleção de uma resposta em um conjunto dado de respostas possíveis. (Minas Gerais, 2009, p. 15)

Segundo o Boletim Pedagógico do Simave (Minas Gerais, 2008), há diferenças entre o $\mathrm{CBC}$ e a Matriz de Referência do Proeb. $\mathrm{O}$ primeiro seria mais amplo e espelharia as diretrizes de ensino cujo desenvolvimento deve ser obrigatório para todos os alunos, enquanto a Matriz de Referência para a avaliação em larga escala seria apenas uma amostra representativa do CBC. O documento faz uma analogia, solicitando ao professor que "imagine a Matriz de Referência para avaliação em larga escala como uma bússola indicativa do que será avaliado, informando o que se espera dos alunos naquele período da escolaridade" (Minas Gerais, 2008, p. 20).

A Matriz de Referência é formada por um conjunto de descritores agrupados em quatro temas: Espaço e Forma, Grandezas e Medidas, Números e Operaçóes (álgebra e funçôes) e Tratamento da Informação. Os descritores descreveriam uma habilidade e explicitariam dois pontos básicos do que se pretende avaliar: o conteúdo programático e o nível de operação mental necessário para a aprendizagem.

No citado documento, encontrou-se a definição de habilidade: "é a capacidade de o aluno mobilizar um conjunto de recursos, entre eles o conhecimento, para realizar determinadas açóes e ser competente na soluçáo de problemas ou situaçóes propostas" (Minas Gerais, 2009, p. 13).

Há, nas Matrizes de Referência, segundo o documento, competências consideradas básicas, as quais se espera que os estudantes tenham desenvolvido ao término de um período de sua escolarização. "Poderíamos comparar a Matriz de Referência para Avaliação a um mapa cognitivo, uma vez que as habilidades nela relacionadas nos permitem compreender os processos de desenvolvimento e aprendizagem vivenciados pelos alunos em diferentes áreas do conhecimento" (Minas Gerais, 2009, p. 14).

Muito embora o conceito de habilidade tenha sido objeto de atençâo, conforme se acaba de ilustrar, năo foi encontrada a definiçáo de competência nos documentos oficiais analisados, relativos ao Simave. 
O Boletim Pedagógico apresenta quadros que sintetizam a relaçáo entre os domínios, as competências e os descritores da Matriz de Referência. Com base neles, apresenta-se o quadro 1, que mostra os agrupamentos dos descritores e das competências nos domínios de interesse deste trabalho (Espaço e Forma e Grandezas e Medidas). São destacados em negrito os descritores relativos à geometria espacial.

Quadro 1 - Domínios, competências e descritores - $9^{\circ}$ ano do EF e $3^{\circ}$ ano do EM

\begin{tabular}{|c|c|c|}
\hline \multicolumn{3}{|c|}{$9^{\circ}$ ano do ensino fundamental } \\
\hline Dominio & Competências & $\begin{array}{ll}\text { Descritores } \\
\end{array}$ \\
\hline \multirow[t]{4}{*}{$\begin{array}{l}\text { ESPAÇO E } \\
\text { FORMA }\end{array}$} & $\begin{array}{l}\text { Localizar objetos em } \\
\text { representaçōes do espaço }\end{array}$ & $\begin{array}{l}\text { D1 Identificar a localização/movimentaçăo de pessoas e objetos } \\
\text { em mapas, croquis e outras representaçóes gráficas. } \\
\text { D9 identificar e localizar pontos no plano cartesiano e suas } \\
\text { coordenadas e vice-versa. }\end{array}$ \\
\hline & $\begin{array}{l}\text { Identificar figuras } \\
\text { geométricas e suas } \\
\text { propriedades }\end{array}$ & $\begin{array}{l}\text { D2 Identificar propriedades de figuras tridimensionais, } \\
\text { relacionando-as com suas planificaçōes. } \\
\text { D3 Identificar propriedades de triângulos pela comparação de } \\
\text { medidas de lados e ângulos. } \\
\text { D4 Identificar relação entre quadriláteros por meio de suas } \\
\text { propriedades. }\end{array}$ \\
\hline & $\begin{array}{l}\text { Reconhecer } \\
\text { transformaçóes no plano }\end{array}$ & $\begin{array}{l}\text { D5 Reconhecer a conservação ou modificação de medidas dos } \\
\text { lados, do perimetro, da área em aplicaçăo e/ou redução de } \\
\text { figuras poligonais usando malhas quadrieuladas. } \\
\text { D6 Reconhecer ângulo como: mudança de direção ou giro, area } \\
\text { delimitada por duas semi-retas de mesma origem. } \\
\text { D7 identificar propriedades de figuras semelhantes construídas } \\
\text { com transformaçóes (redução, ampliação, translação e } \\
\text { rotação). }\end{array}$ \\
\hline & $\begin{array}{l}\text { Aplicar relações e } \\
\text { propriedades }\end{array}$ & $\begin{array}{l}\text { D8 Utilizar propriedades dos polígonos regulares (soma de seus } \\
\text { ângulos internos, número de diagonais, cálculo da medida de } \\
\text { cada angulo interno). } \\
\text { D10 Utilizar relaçóes métricas do triângulo retângulo e o Teorema } \\
\text { de Pitágoras. } \\
\text { D11 Utilizar as propriedades e relaçóes dos elementos do círculo e } \\
\text { da circunferência. }\end{array}$ \\
\hline \multirow[t]{3}{*}{$\begin{array}{l}\text { GRANDEZASE } \\
\text { MEDIDAS }\end{array}$} & $\begin{array}{l}\text { Utilizar sistemas de } \\
\text { medidas }\end{array}$ & D14 Utilizar as relaçōes entre diferentes unidades de medida. \\
\hline & Medir grandezas & $\begin{array}{l}\text { D12 Resolver situações-problema envolvendo o cálculo do } \\
\text { perímetro e da área de figuras planas. } \\
\text { D13 Utilizar as noçöes de volume. }\end{array}$ \\
\hline & $\begin{array}{l}\text { Estimar e comparar } \\
\text { grandezas }\end{array}$ & \\
\hline \multicolumn{3}{|r|}{$3^{\circ}$ ano do ensino médio } \\
\hline Domínio & Competências & Descritores \\
\hline \multirow[t]{4}{*}{$\begin{array}{l}\text { ESPAÇOE } \\
\text { FORMA }\end{array}$} & $\begin{array}{l}\text { Identificar figuras } \\
\text { geométricas e suas } \\
\text { propriedades }\end{array}$ & $\begin{array}{l}\text { D1 Reconhecer a planificação de figuras tridimensionais mais } \\
\text { usuais (prismas, pirâmides, paralelepípedo, cubo, cilindro } \\
\text { e cone). } \\
\text { D4 interpretar geometricamente os coeficientes da equação de } \\
\text { uma reta. }\end{array}$ \\
\hline & $\begin{array}{l}\text { Aplicar relaçōes e } \\
\text { propriedades }\end{array}$ & $\begin{array}{l}\text { D5 Construir a equação da reta que passa por dois pontos dados. } \\
\text { D2 Resolver situaçóes-problema, no plano, que envolvam razão } \\
\text { trigonométrica no triângulo retángulo (seno, cosseno, } \\
\text { tangente). } \\
\text { D3 Calcular a distancia entre dois pontos no plano cartesiano }\end{array}$ \\
\hline & $\begin{array}{l}\text { Localizar objetos em } \\
\text { representaçöes do espaço }\end{array}$ & \\
\hline & $\begin{array}{l}\text { Reconhecer } \\
\text { transformaçōes no plano }\end{array}$ & \\
\hline \multirow[t]{3}{*}{$\begin{array}{l}\text { GRANDEZAS E } \\
\text { MEDIDAS }\end{array}$} & Medir grandezas & $\begin{array}{l}\text { D6 Utilizar o cálculo de perímetro de figuras planas. } \\
\text { D7 Utilizar o cálculo de áreas de figuras planas. } \\
\text { D8 Resolver situaçőes-problema envolvendo a área total de } \\
\text { figuras tridimensionais (prisma, pirâmide, cilindiro, cone, } \\
\text { esfera, paralelepípedo). } \\
\text { D9 Resolver situaçóes-problema envolvendo o volume de um } \\
\text { sólido (prisma, pirâmide, cilindro, cone, esfera, } \\
\text { paralelepipedo). }\end{array}$ \\
\hline & $\begin{array}{l}\text { Utilizar sistemas de } \\
\text { medidas }\end{array}$ & \\
\hline & $\begin{array}{l}\text { Estimar e comparar } \\
\text { grandezas }\end{array}$ & \\
\hline
\end{tabular}


Conforme pode ser verificado no quadro 1 , não há descritores diretamente ligados a algumas competências.

Os testes de proficiência escolar foram compostos por itens de múltipla escolha, redigidos com base nas Matrizes de Referência de Língua Portuguesa e de Matemática do Proeb/Simave, que apresentaram boa qualidade técnica e pedagógica.

Os alunos responderam a testes relativamente pequenos, de 39 itens, fundamentados numa coleção de 169 itens, para cada um dos períodos escolares e áreas de conhecimento, o que deu origem a 13 blocos de 13 itens. Por meio de uma combinaçáo de blocos balanceados, foram compostos 26 diferentes cadernos de testes, com 39 itens cada um.

O presente trabalho pretendeu analisar as competências destacadas em negrito no quadro 1, realizando duas abordagens: a primeira tratou dos aspectos teóricos envolvidos nessas habilidades, tendo em vista a bibliografia já apontada. A segunda, a abordagem quantitativa, permitiu verificar o nível de formação dessa habilidade nos alunos, buscando fundamentação para possíveis implicaçóes pedagógicas para o ensino de geometria.

\section{OBJETIVOS DA PESQUISA}

$O$ estudo aqui apresentado pretende:

1) Analisar as questóes de geometria espacial das provas de Matemática do Proeb/Simave direcionadas aos alunos do ensino fundamental e médio, em 2006, 2007 e 2008, de acordo com os critérios:
a) forma de apresentaçáo das informaçóes (se verbal, pictórica ou mista);
b) estrutura conceitual requerida (se geométrica, algébrica, aritmética, espacial ou mista) e o nível de formação conceitual em geometria;
c) habilidades espaciais requeridas (componente espacial da habilidade matemática).

2) Analisar o desempenho de alunos do ensino fundamental e médio nas questóes citadas. 


\section{METODOLOGIA}

O Centro de Políticas Públicas e Avaliação da Educação (CAEd) ${ }^{3}$ da Universidade Federal de Juiz de Fora disponibilizou para esta pesquisa os bancos de dados relativos às avaliaçōes de 2006, 2007 e 2008.

Os dados acerca das matrizes de referência, dos conteúdos curriculares e das escalas de proficiência foram obtidos por meio dos boletins pedagógicos e de outros documentos disponibilizados no site da Secretaria da Educação de Minas Gerais.

\section{RESULTADOS E DISCUSSÃO}

A distribuiçáo dos sujeitos por série e ano é mostrada na tabela 2.

Tabela 2 - Distribuição dos sujeitos da pesquisa por série

\begin{tabular}{llc}
\hline Ano & Série & No de sujeitos \\
\hline \multirow{2}{*}{2006} & $9 \mathrm{EF}$ & 222.486 \\
& $3 \mathrm{EM}$ & 136.497 \\
2007 & $9 \mathrm{EF}$ & 230.090 \\
& $3 \mathrm{EM}$ & 135.981 \\
2008 & $9 \mathrm{EF}$ & 230.164 \\
& $3 \mathrm{EM}$ & 144.024 \\
Subtotal & $9 \mathrm{EF}$ & 682.740 \\
& $3 \mathrm{EM}$ & 416.502 \\
\hline Total & & $\mathbf{1 . 0 9 9 . 2 4 2}$ \\
\hline
\end{tabular}

\subsection{O desempenho na prova Proeb}

Os testes que compóem as provas são montados seguindo o modelo denominado Blocos Incompletos Balanceados (BIB), no qual os itens são organizados em blocos que compóem cadernos diferentes, de forma a contemplar todas as habilidades avaliadas em cada um dos segmentos: do $1^{\circ}$ ao $5^{\circ}$ ano e do $6^{\circ}$ ao $9^{\circ}$ ano do ensino fundamental e do $1^{\circ}$ ao $3^{\circ}$ ano do ensino médio.

Para cada segmento avaliado, são utilizados 169 itens, agrupados em 13 blocos com 13 itens cada. Aplicando os critérios do BIB, foram gerados 26 modelos diferentes de cadernos de teste, sendo cada um composto por 3 blocos de itens, um deles comum com outro caderno. Segundo o $\mathrm{BP}$, essa configuraçáo não deixa o teste cansativo, pois cada aluno responde a 39 itens apenas.

${ }^{3}$ Agradecimentos à equipe de Análise e Medidas do CAEd - Wellington Silva (Coordenador), Ailton Fonseca Galvão, Clayton Vale e Rafael Oliveira. 
Para possibilitar a comparabilidade dos resultados de Minas Gerais no Simave/Proeb com os resultados do Brasil no Saeb/Inep, 20\% dos itens de todas as séries são comuns a avaliações já realizadas pelo Saeb.

A pontuação para o desempenho varia de 0 a 500 pontos, e os resultados são mostrados na tabela 3. Pode-se verificar que houve aumento nas médias de desempenho nesses três anos, em especial no ensino fundamental.

Tabela 3 - Distribuição das estatísticas do desempenho nas provas Proeb por série e ano

\begin{tabular}{lcccccc}
\hline Estatísticas & \multicolumn{2}{c}{2006} & \multicolumn{2}{c}{2007} & \multicolumn{2}{c}{2008} \\
\hline \multirow{2}{*}{ No de sujeitos $^{\circ} \mathrm{EF}$} & $\mathbf{3} \mathbf{3}^{\circ} \mathrm{EM}$ & $\mathbf{9}^{\circ} \mathrm{EF}$ & $\mathbf{3}^{\circ} \mathrm{EM}$ & $\mathbf{9}^{\circ} \mathrm{EF}$ & $\mathbf{3}^{\circ} \mathrm{EM}$ \\
\cline { 2 - 7 } Mínimo & 222.486 & 136.497 & 230.090 & 135.981 & 230.164 & 144.024 \\
Máximo & 69,38 & 136,13 & 83,10 & 132,71 & 102,37 & 129,73 \\
Média & 411,54 & 440,30 & 411,85 & 442,83 & 428,23 & 455,43 \\
Mediana & 245,4219 & 274,3577 & 249,5485 & 281,9823 & 253,9021 & 281,8347 \\
Desvio padrão & 247,0397 & 274,9902 & 250,1962 & 283,1988 & 254,8325 & 283,1529 \\
& 51,21124 & 53,14978 & 50,25590 & 51,46672 & 50,28269 & 53,44917 \\
\hline
\end{tabular}

Como participam do Simave escolas da rede estadual e municipal de ensino, procurou-se verificar se havia diferenças de desempenho por rede. O resultado é mostrado na tabela 4.

Tabela 4 - Desempenho dos sujeitos por rede (estadual e municipal)

\begin{tabular}{|c|c|c|c|c|c|c|}
\hline Ano & Série & Rede & $\mathbf{N}$ & Média & $\begin{array}{l}\text { Desvio } \\
\text { padrão }\end{array}$ & Estatística \\
\hline \multirow{4}{*}{2006} & \multirow{2}{*}{$9 \circ \mathrm{EF}$} & Estadual & 175.290 & 246,2647 & 51,06049 & $t_{(222484)}=14,969$ \\
\hline & & Municipal & 47.196 & 242,2915 & 51,64757 & $p=0,000$ \\
\hline & \multirow{2}{*}{$3^{\circ} \mathrm{EM}$} & Estadual & 132.800 & 274,6239 & 52,99171 & $t_{(136495)}=11,096$ \\
\hline & & Municipal & 3.697 & 264,7946 & 57,74515 & $p=0,000$ \\
\hline \multirow{4}{*}{2007} & \multirow{2}{*}{$9^{\circ} \mathrm{EF}$} & Estadual & 175.431 & 250,9447 & 50,09868 & $t_{(230088)}=23,904$ \\
\hline & & Municipal & 54.659 & 245,0673 & 50,49757 & $p=0,000$ \\
\hline & \multirow{2}{*}{$3^{\circ} \mathrm{EM}$} & Estadual & 132.342 & 282,4465 & 51,27328 & $t_{(135979)}=20,085$ \\
\hline & & Municipal & 3.639 & 265,1021 & 55,49459 & $p=0,000$ \\
\hline \multirow{4}{*}{2008} & \multirow{2}{*}{$9^{\circ} \mathrm{EF}$} & Estadual & 174.585 & 255,8079 & 49,86499 & $t_{(230162)}=32,301$ \\
\hline & & Municipal & 55.579 & 247,9155 & 51,11307 & $p=0,000$ \\
\hline & \multirow{2}{*}{$3^{\circ} \mathrm{EM}$} & Estadual & 140.693 & 282,2320 & 53,26268 & $t_{(144022)}=18,354$ \\
\hline & & Municipal & 3.331 & 265,0541 & 58,39661 & $p=0,000$ \\
\hline
\end{tabular}


Pode-se verificar que, nos anos e nas séries analisadas, os alunos da rede estadual tiveram desempenho melhor que os alunos da rede municipal.

\subsection{A análise das questốes}

A tarefa de análise das questóes também foi possibilitada pelo CAEd ${ }^{4}$, que disponibilizou as imagens dos itens referentes às avaliações de 2006, 2007 e 2008.

$\mathrm{O}$ quadro 2 mostra as questóes analisadas. Colocou-se como código a série, o ano, o descritor e uma sequência numérica. Várias das questóes analisadas apareceram em dois ou três anos, na mesma série. Outras eram comuns às duas séries. Assim, para facilitar a exposição, as questóes foram agrupadas por descritores.

Como as questóes são consideradas sigilosas pelo $\mathrm{CAEd}^{5}$, as imagens não podem ser divulgadas. Desse modo, as análises a seguir serão ilustradas pelas imagens constantes do Boletim Pedagógico (BP) e do documento Matrizes de Referência (MR) do $9^{\circ}$ ano do $\mathrm{EF}$ e do $3^{\circ}$ ano do $\mathrm{EM}$, de matemática.

Questöes referentes ao descritor D2: identificar propriedades de figuras tridimensionais, relacionando-as com suas planificaçöes $\left(9^{\circ} \mathrm{EF}\right)$

O objetivo desse descritor, segundo o BP, é avaliar, "por meio dos itens relativos a este descritor, a capacidade de o aluno reconhecer as propriedades comuns e as diferenças entre as figuras bidimensionais e tridimensionais, relacionando-as com as suas planificaçóes" (Minas Gerais, 2009). No quadro 3 sáo mostrados exemplos de questôes com esse objetivo.

\footnotetext{
${ }^{4}$ Agradecimentos à equipe do Banco de Itens: Verônica Mendes Vieira (Coordenadora) e Mayra da Silva Moreira.

5 A autora deste trabalho assinou um termo de compromisso para não divulgar as imagens dos itens.
} 
Quadro 2 - Questões analisadas, de acordo com a série, o ano e o descritor

\begin{tabular}{|c|c|c|c|c|}
\hline Código & Série & Ano & Descritor & Descrição \\
\hline 9EF-2006- D2-1 & 9EF & 2006 & D2 & \multirow{4}{*}{$\begin{array}{l}\text { Identificar propriedades de figuras tridimensionais, relacionando- } \\
\text { as com suas planificações. }\end{array}$} \\
\hline 9EF-2006- D2-2 & $9 \mathrm{EF}$ & 2006 & D2 & \\
\hline 9EF-2006- D2-3 & 9EF & 2006 & D2 & \\
\hline 9EF-2006- D2-4 & 9EF & 2006 & $\mathrm{D} 2$ & \\
\hline 3EM-2006- D1-1 & 3EM & 2006 & D1 & \multirow{2}{*}{$\begin{array}{l}\text { Reconhecer a planificação de figuras tridimensionais mais usuais } \\
\text { (prismas, pirâmides, paralelepipedo, cubo, cilindro e cone). }\end{array}$} \\
\hline 3EM-2006-D1-2 & 3EM & 2006 & D1 & \\
\hline 3EM-2006- D8- 8 & 3EM & 2006 & D8 & $\begin{array}{l}\text { Resolver situações-problema envolvendo a área total de figuras } \\
\text { tridimensionais (prisma, pirâmide, cilindro, cone, esfera, } \\
\text { paralelepípedo). }\end{array}$ \\
\hline 3EM-2006- D9-1 & 3EM & 2006 & D9 & \multirow{3}{*}{$\begin{array}{l}\text { Resolver situações-problema envolvendo o volume de um sólido } \\
\text { (prisma, pirâmide, cilindro, cone, esfera, paralelepípedo). }\end{array}$} \\
\hline 3EM-2006- D9-2 & 3EM & 2006 & D9 & \\
\hline 3EM-2006-D9-3 & 3EM & 2006 & D9 & \\
\hline 9EF-2007- D2-1 & 9EF & 2007 & $\mathrm{D} 2$ & \multirow{4}{*}{$\begin{array}{l}\text { Identificar propriedades de figuras tridimensionais, relacionando- } \\
\text { as com suas planificações. }\end{array}$} \\
\hline 9EF-2007- D2-2 & 9EF & 2007 & $\mathrm{D} 2$ & \\
\hline 9EF-2007-D2-3 & 9EF & 2007 & $\mathrm{D} 2$ & \\
\hline 9EF-2007-D2-4 & 9EF & 2007 & D2 & \\
\hline 9EF-2007-D13-1 & 9EF & 2007 & D13 & \multirow{2}{*}{ Utilizar as noções de volume. } \\
\hline 9EF-2007-D13-2 & 9EF & 2007 & D13 & \\
\hline 3EM-2007- D1-1 & 3EM & 2007 & D1 & \multirow{3}{*}{$\begin{array}{l}\text { Reconhecer a planificação de figuras tridimensionais mais usuais } \\
\text { (prismas, pirâmides, paralelepipedo, cubo, cilindro e cone) }\end{array}$} \\
\hline 3EM-2007-D1-2 & 3EM & 2007 & D1 & \\
\hline 3EM-2007-D1-3 & 3EM & 2007 & D1 & \\
\hline 3EM-2007-D8 & 3EM & 2007 & D8 & $\begin{array}{l}\text { Resolver situações-problema envolvendo a área total de figuras } \\
\text { tridimensionais (prisma, pirâmide, cilindro, cone, esfera, } \\
\text { paralelepípedo). }\end{array}$ \\
\hline 3EM-2007- D9-1 & $3 E M$ & 2007 & D9 & \multirow{2}{*}{$\begin{array}{l}\text { Resolver situações-problema envolvendo o volume de um sólido } \\
\text { (prisma, pirâmide, cilindro, cone, esfera, paralelepípedo). }\end{array}$} \\
\hline 3EM-2007-D9-2 & 3EM & 2007 & D9 & \\
\hline 9EF-2008- D2 & 9EF & 2008 & $\mathrm{D} 2$ & $\begin{array}{l}\text { Identificar propriedades de figuras tridimensionais, relacionando- } \\
\text { as com suas planificações }\end{array}$ \\
\hline 3EM-2008-D1-1 & $3 \mathrm{EM}$ & 2008 & D1 & \multirow{5}{*}{$\begin{array}{l}\text { Reconhecer a planificação de figuras tridimensionais mais usuais } \\
\text { (prismas, pirâmides, paralelepípedo, cubo, cilindro e cone) }\end{array}$} \\
\hline 3EM-2008-D1-2 & 3EM & 2008 & D1 & \\
\hline 3EM-2008-D1-3 & 3EM & 2008 & D1 & \\
\hline 3EM-2008-D1-4 & 3EM & 2008 & D1 & \\
\hline 3EM-2008-D1-5 & 3EM & 2008 & D1 & \\
\hline 3EM-2008-D8 & 3EM & 2008 & D8 & $\begin{array}{l}\text { Resolver situações-problema envolvendo a área total de figuras } \\
\text { tridimensionais (prisma, pirâmide, cilindro, cone, esfera, } \\
\text { paralelepipedo). }\end{array}$ \\
\hline 3EM-2008-D9-1 & 3EM & 2008 & D9 & \multirow{3}{*}{$\begin{array}{l}\text { Resolver situações-problema envolvendo o volume de um sólido } \\
\text { (prisma, pirâmide, cilindro, cone, esfera, paralelepipedo). }\end{array}$} \\
\hline 3EM-2008-D9-2 & $3 \mathrm{EM}$ & 2008 & D9 & \\
\hline 3EM-2008-D9-3 & $3 E M$ & 2008 & D9 & \\
\hline
\end{tabular}


Quadro 3 - Exemplos de questōes referentes ao descritor D2: identificar propriedades de figuras tridimensionais, relacionando-as com suas planificações ( $9^{\circ} \mathrm{EF}$ )

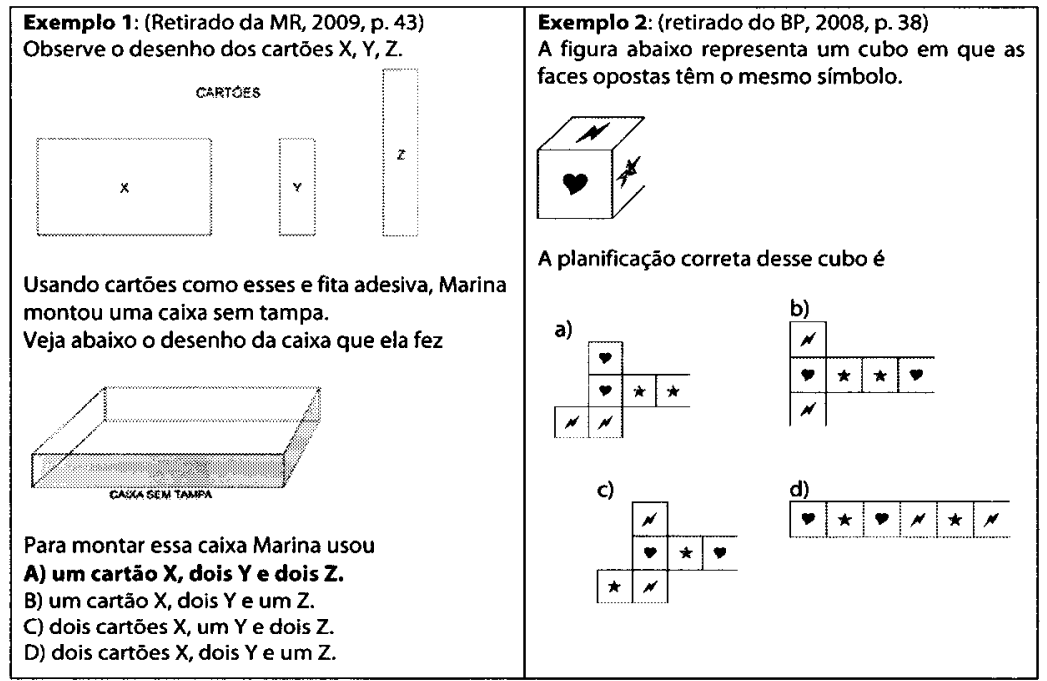

Foram analisadas sete questóes relativas a esse descritor, algumas semelhantes aos exemplos apresentados. Na grande maioria, o enunciado era pictórico e em poucos era exigido o conceito de cubo ou paralelepípedo, uma vez que eram apresentados o nome e a figura correspondente. A maioria dos itens, apesar da referência a figuras familiares, apresentava planificaçóes distintas daquelas que normalmente aparecem nos livros didáticos. Isso implica que tais questóes requerem habilidade espacial, em um nível complexo de operaçóes mentais ${ }^{6}$, pois são direcionadas a alunos do ensino fundamental.

Questöes referentes ao descritor D1: reconhecer a planificaçäo de figuras tridimensionais mais usuais (prismas, pirâmides, paralelepipedo, cubo, cilindro e cone) ( $\left.3^{\circ} E M\right)$

Avalia-se, por meio dos itens relativos a esse descritor, a habilidade de o aluno reconhecer as planificaçóes dos poliedros, como prismas, pirâmides e troncos de pirâmides; e dos corpos redondos, como cilindros, cones e troncos de cones. No quadro 4 são mostrados exemplos de questóes com esse objetivo.

${ }^{6}$ A complexidade das operações mentais referentes à formaçâo e à manipulação de imagens está ligada à ativação dos sistemas cerebrais, conforme a teoria de Kosslyn (1995). A formação da imagem da planificação de uma figura pode ativar desde um sistema de memória até um sistema complexo que depende de informaçôes e de conhecimentos prévios, além de inspeçóes e movimentaçöes de imagens. 
Quadro 4 - Exemplos de questões referentes ao descritor D1: reconhecer a planificação de figuras tridimensionais mais usuais ( $3^{\circ} \mathrm{EM}$ )

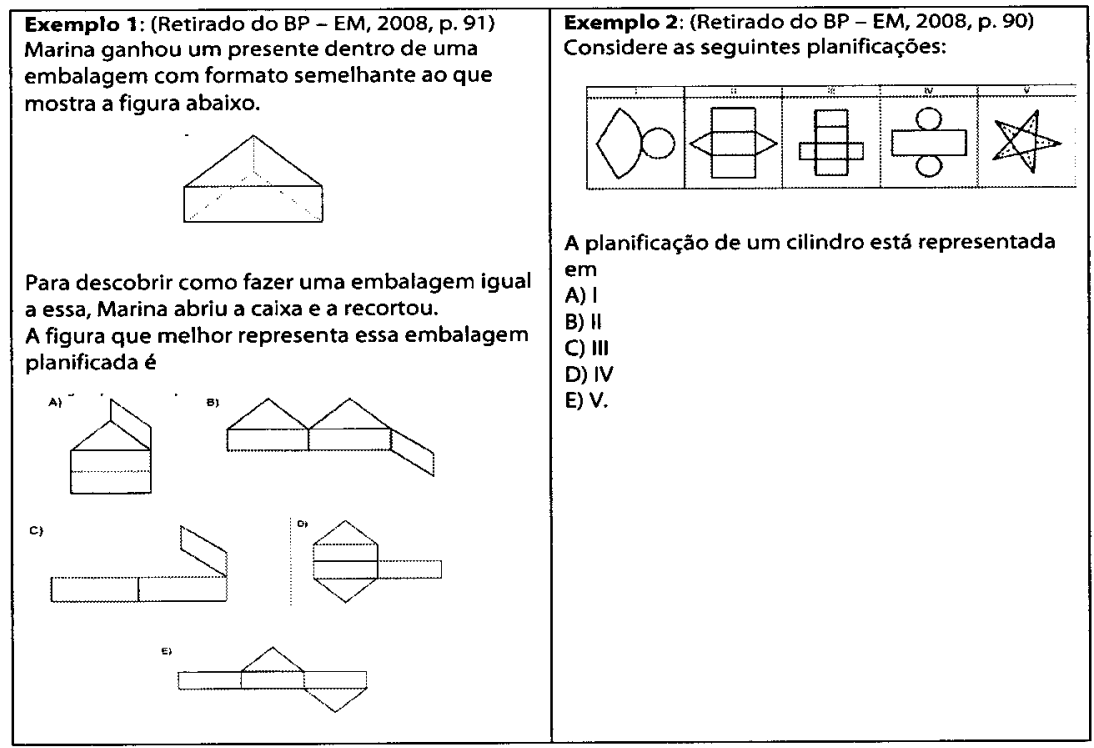

Foi possível constatar que, entre as dez questóes analisadas, quase todas apresentavam desenhos de planificaçáo semelhantes aos que aparecem nos livros didáticos. Assim, a situaçáo para o ensino médio é oposta à do ensino fundamental, comentada no parágrafo anterior. Apesar de as questóes se referirem a vários conceitos, a maioria delas nâo avaliava o reconhecimento e a nomeaçáo (características do Nível 1 de formaçáo conceitual), conforme pode ser verificado no Exemplo 1 do quadro 4. Nota-se que, nesse exemplo, o conceito de prisma náo é avaliado. Já no Exemplo 2, avalia-se o conceito de cilindro na relação com a planificação, o que exigiria do aluno a análise de algumas propriedades, características do Nível 2 de formaçáo conceitual. Pode-se notar, nesse caso, a simplicidade dos desenhos apresentados, o que significa que a questão não requer habilidade espacial com complexidade de operaçóes mentais.

Questôes referentes ao descritor D8: resolver situaçóes-problema envolvendo a área total de figuras tridimensionais (prisma, pirâmide, cilindro, cone, esfera, paralelepipedo) (3० EM)

Os itens relativos a esse descritor avaliam a habilidade de o aluno resolver problemas que envolvam o cálculo da medida da área total dos sólidos geométricos. Entre os poliedros, o descritor sugere que poderiam ser explorados os prismas e as 
pirâmides regulares e irregulares; e entre os sólidos de revolução, os cilindros, os cones e as esferas. $\mathrm{O}$ quadro 5 mostra um exemplo de questão relativa a esse descritor.

Quadro 5 - Exemplo de questão referente ao descritor D8: resolver situações-problema envolvendo a área total de figuras tridimensionais ( $\left.3^{\circ} \mathrm{EM}\right)$

Exemplo: (Retirado do BP - EM, 2008, p. 90)

Uma embalagem de papelão tem a forma de um bloco retangular de dimensões $4 \mathrm{~cm}, 6 \mathrm{~cm}$ e $12 \mathrm{~cm}$.

Quantos $\mathrm{cm}^{2}$ de papelão são utilizados na construção dessa caixa?
A) 22
B) 24
C) 44
D) 144
E) 288

Foram identificadas apenas três questóes desse tipo, em que náo se exigia a formaçáo de conceitos. $\mathrm{O}$ seu enunciado era pictórico, diferentemente do exemplo apresentado.

Questöes referentes ao descritor D13: utilizar as noçóes de volume (9० EF)

Avalia-se, por meio dos itens relativos a esse descritor, a habilidade de o aluno calcular o volume ou a capacidade de sólidos geométricos, conforme mostra o quadro 6 .

Quadro 6 - Exemplo de questão referente ao descritor D13: utilizar noções de volume $\left(9^{\circ} \mathrm{EF}\right)$

Exemplo: (Retirado do BP - EF, 2008, p. 50)

Fabiana colocará vários cubos pequenos, de $10 \mathrm{~cm}$ de lado, dentro da embalagem representada abaixo:

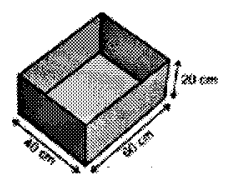

Quantos cubos, no máximo, ela colocará na embalagem sem ultrapassar sua altura?
A) 10
B) 12
C) 24
D) 48 
Foram identificadas apenas duas questóes referentes a esse descritor, que solicitavam a relação entre dois volumes: o da figura apresentada e o de outra em que eram dadas as suas medidas. Considera-se que esse tipo de questão tem elementos para que seja considerada problema, pois há a necessidade de estabelecimento de relaçóes entre os conceitos de volume e de divisão.

Questóes referentes ao descritor $D$ 9: resolver situaçóes-problema envolvendo o volume de um sólido (prisma, pirâmide, cilindro, cone, esfera, paralelepipedo) (3० EM)

Os itens relativos a esse descritor avaliam a habilidade de o aluno, com base em uma figura tridimensional dada ou identificada no problema, calcular a medida do seu volume, conforme mostra o quadro 7.

Quadro 7 - Exemplo de questão referente ao descritor D9: resolver situações-problema envolvendo o volume de um sólido ( $\left.3^{\circ} \mathrm{EM}\right)$

Exemplo: (Retirado do BP - EM, 2008, p. 72)

Uma embalagem de talco de forma cilíndrica possui 15 centímetros de altura e base com 3 centímetros de raio. Qual é o volume máximo, em $\mathrm{cm}^{2}$, de talco que essa embalagem comporta?
$\begin{array}{llll}\text { A) } 540 \pi & \text { B) } 180 \pi & \text { C) } 135 \pi\end{array}$
D) $90 \pi$ E) $45 \pi$

Apesar de essas questóes serem relativas ao ensino médio, observou-se que a solução requer o uso automático de fórmulas. As oito questóes analisadas, classificadas como estrutura aritmética, não foram consideradas problemas, uma vez que a solução náo requer a relação entre conceitos, nem o uso de estratégias.

A tabela 5 resume o desempenho dos alunos por grupos de questão, de acordo com o descritor. 
Tabela 5 - Distribuição das questões por descritor e média de acertos

\begin{tabular}{|c|c|c|}
\hline Descritor & $\begin{array}{l}\text { No de questöes } \\
\text { analisadas }\end{array}$ & $\begin{array}{l}\text { Média de } \\
\text { acertos (\%) }\end{array}$ \\
\hline $\begin{array}{l}\text { D2 Identificar propriedades de figuras tridimensionais, relacionando-as com suas } \\
\text { planificaçōes (9० EF) }\end{array}$ & 09 & 48,96 \\
\hline $\begin{array}{l}\text { D1 Reconhecer a planificação de figuras tridimensionais mais usuais (prismas, } \\
\text { pirâmides, paralelepipedo, cubo, cilindro e cone) ( }\left(3^{\circ} \mathrm{EM}\right)\end{array}$ & 10 & 63,07 \\
\hline $\begin{array}{l}\text { D8 Resolver situaçōes-problema envolvendo a área total de figuras tridimensionais } \\
\left.\text { (prisma, pirâmide, cilindro, cone, esfera, paralelepípedo) ( } 3^{\circ} \mathrm{EM}\right)\end{array}$ & 03 & 30,16 \\
\hline D13 Utilizar as noções de volume (9० EF) & 02 & 26,75 \\
\hline $\begin{array}{l}\text { D9 Resolver situações-problema envolvendo o volume de um sólido (prisma, } \\
\left.\text { pirâmide, cilindro, cone, esfera, paralelepípedo) ( } 3^{\circ} \mathrm{EM}\right)\end{array}$ & 08 & 38,41 \\
\hline Total & 32 & 41,47 \\
\hline
\end{tabular}

A tabela 6 apresenta o número de questóes e as médias de acerto em cada uma das categorias analisadas.

Tabela 6 - Distribuição das questões por categorias de análise e porcentagem média de acertos

\begin{tabular}{llcc}
\hline \multicolumn{1}{c}{ Variáveis } & Categorias & $\begin{array}{c}\text { No de } \\
\text { questões }\end{array}$ & $\begin{array}{c}\text { Média de } \\
\text { acertos (\%) }\end{array}$ \\
\hline Enunciado da & Pictórico & 25 & 49,372 \\
questão & Verbal & 4 & 45,700 \\
& Misto & 3 & 33,133 \\
\hline \multirow{2}{*}{ Conceito (figura) } & Paralelepípedo & 12 & 48,383 \\
envolvido & Cubo & 08 & 43,237 \\
& Cilindro & 05 & 50,140 \\
& Pirâmide & 04 & 30,167 \\
\hline Nível de & Outros & 03 & 58,367 \\
conceituação & Nenhum & 13 & 49,838 \\
& Nivel 2 & 19 & 45,715 \\
\hline \multirow{2}{*}{ Estrutura } & Espacial (habilidade espacial-planificação) & & \\
& Sem complexidade & 12 & 63,875 \\
& Com complexidade & 07 & 42,671 \\
\hline Relações & Aritmética (cálculo de áreas e volumes) & 13 & 34,715 \\
requeridas & Sem relações & 29 & 49,527 \\
\hline
\end{tabular}

\section{CONSIDERAÇÕES FINAIS}

Este trabalho procurou levantar alguns questionamentos acerca da Matriz de Referência das provas do Proeb/Simave. Analisou também o desempenho de mais de um milhão de alunos da rede estadual e municipal de Minas Gerais. A análise dos dados relativos ao desempenho dos alunos do $9^{\circ}$ ano do $\mathrm{EF}$ e do $3^{\circ}$ ano do EM nas provas de matemática de 2006, 2007 e 2008, nas questões de geometria espacial, permite afirmar que há falhas no desenvolvimento de vários conceitos e procedimentos relativos a esses níveis de ensino. 
As questóes das provas foram discutidas, tomando por base os descritores, as competências e o conhecimento teórico que se tem a respeito de aspectos cognitivos da formaçáo de conceitos e de habilidades e acerca de tipos de problemas geométricos.

Verificou-se que é relativamente baixo o nível de formaçáo conceitual exigido em relação às figuras geométricas espaciais. Várias questóes não avaliam conceitos, pois as figuras são apresentadas no enunciado e, portanto, não necessitam de nomeação. Não foram identificadas, mesmo no ensino médio, questóes que exigissem o estabelecimento de relaçóes entre conceitos, nem a deduçâo formal de algumas propriedades, o que garantiria os níveis três e quatro, respectivamente, conforme a teoria de Van Hiele (1986) sobre formação conceitual.

As propriedades geométricas solicitadas pelas questóes analisadas estão restritas à planificação dos principais sólidos e, no caso do ensino médio, as planificaçóes são aquelas tradicionais que figuram nos livros didáticos. Assim, mesmo no ensino médio, não sâo apresentadas questôes que requeiram conhecimento mais aprofundado acerca das propriedades das figuras tridimensionais. Da mesma forma, outras habilidades importantes na geometria espacial - como as relacionadas à secção ou a sólidos de revolução, verificadas em Krutetsky (1976) e em Viana (2005), e que exigiriam operaçôes mentais mais complexas - também não são sugeridas.

O reconhecimento da planificação correta em uma questáo de múltipla escolha, com desenhos tradicionais, pode não corresponder ao descritor D2 (Identificar propriedades de figuras tridimensionais, relacionando-as com suas planificaçóes) e à competência "Identificar figuras geométricas e suas propriedades". As figuras geométricas têm várias propriedades, verificáveis em vários níveis de complexidade, e a habilidade de planificaçáo poderia até demonstrar a identificação de algumas delas, mas não de outras. Por exemplo, a competência para reconhecer propriedades de um cubo e de um tetraedro regular, de modo a agrupá-los como poliedros regulares, pode não estar relacionada à habilidade de planificação desses dois sólidos geométricos. Outro exemplo seria a identificação de diagonais congruentes de um paralelepípedo, competência que nâo precisa estar relacionada à habilidade de planificação dessa figura.

Questóes que solicitam relacionar um sólido com a sua planificação correta podem não se constituir em problemas genuínos e, dessa forma, não avaliar a habilidade de planificação. Conforme documentos oficiais, a habilidade foi definida como a capacidade de o aluno mobilizar um conjunto de recursos, entre eles o conhecimento, para realizar determinadas açóes e ser competente na soluçáo de 
problemas ou situações propostas. Se forem apresentados desenhos de planificação tradicionais de livros didáticos, isso se constitui em um exercício - cuja soluçáo depende de memorização da relação figura $\leftrightarrow$ planificação - , e não em um problema que exigiria do aluno empregar recursos cognitivos para solucioná-lo.

Embora haja diferenças entre os Conteúdos Básicos Comuns (CBC) e a Matriz de Referência do Proeb, os próprios documentos da Secretaria da Educação afirmam que essa é uma amostra representativa do CBC. A prova Proeb foi feita de modo a espelhar o que se espera dos alunos naqueles períodos da escolaridade.

Dessa forma, como as matrizes e as provas do Simave reduzem o conhecimento de geometria espacial a níveis elementares de formaçáo e de habilidades, pode-se supor que os professores também reduzam o ensino desses conteúdos dentro desse enfoque, guiados pela "bússola", conforme afirmação dos documentos oficiais.

Assim, espera-se que as análises e discussóes feitas possam servir de reflexáo para que sejam revistos alguns descritores e competências, para melhor situar a geometria espacial, no que se refere à formação conceitual e às habilidades.

\section{REFERÊNCIAS BIBLIOGRÁFICAS}

KOSSLYN, S. M. Image and brain: the resolution of the imagery debate. Cambridge: MIT, 1995.

KRUTETSKY, V. A. The Psychology of mathematical abilities in schoolchildren. Chicago: University of Chicago Press, 1976.

MINAS GERAIS. Secretaria de Educação. Boletim pedagógico de avaliação da educação: Simave/Proeb-2008 - CAEd, v. 2, jan./dez. 2008, Juiz de Fora: Faculdade de Educação, UFJF, 2008.

Matrizes de Referência para Avaliação. Sistema Mineiro de Avaliação da Educação Pública. Matemática (Simave). Juiz de Fora: Faculdade de Educação/CAEd, UFJF, 2009.

PIROLA, N. A. Solução de problemas geométricos: dificuldades e perspectivas. 2000. Tese (Doutorado) - Universidade Estadual de Campinas, Campinas, 2000.

PIROLA, N. A.; BRITO, M. R. F. A Formação de conceitos de triângulo e de paralelogramo em alunos da escola elementar. In: BRITO, M. R. F. Psicologia da Educação Matemática: teoria e pesquisa. Florianópolis: Insular, 2001.

RESENDE, J. M.; VIANA, O. A. A Habilidade espacial de alunos do ensino médio: análise e reaplicação de questões das provas Enem referentes à geometria espacial. In: ENCONTRO REGIONAL DE EDUCAÇÃO MATEMÁTICA DE IPATINGA, 2008, Ipatinga. Anais... Ipatinga, MG.

REZI, V. Um estudo exploratório sobre os componentes das habilidades matemáticas presentes no pensamento em geometria. 2001. Dissertação (Mestrado) - Universidade Estadual de Campinas, Campinas, 2001.

STERNBERG, R. J. Psicologia cognitiva. Porto Alegre: Artes Médicas, 2000.

VAN HIELE, P. M. Structure and insight: a theory of Mathematics education. Orlando: Academic Press, 1986.

VIANA, O. A. O Conhecimento geométrico de alunos do Cefam sobre figuras espaciais: um estudo das habilidades e dos níveis 
de conceito. 2000. Dissertação (Mestrado) requeridos pelas questões de geometria do - Universidade Estadual de Campinas, ENC/Enade para a Licenciatura em Matemática. Campinas, 2000.

VIANA, O. A. O Componente espacial da Bolema: Boletim de Educação Matemática, habilidadematemática de alunos do ensinomédio $e$ as relações com o desempenho escolar $e$ as atitudes em relação à matemática e à geometria. 2005. Tese (Doutorado) - Universidade Estadual de Campinas, Campinas, 2005.

. Conceitos e habilidades espaciais

habilidades para geometria espacial avaliadas por questões do Enem. In: SEMINÁRIO INTERNACIONAL DE PESQUISA EM EDUCAÇÃO MATEMÁTICA 4., 2009, Brasília: SIPEM. Anais... 2009b. 